\title{
Implementation of DC voltage controllers on enhancing the stability of multi-terminal DC grids
}

\author{
Moussa Belgacem ${ }^{1}$, Mohamed Khatir ${ }^{2}$, Mohammed Abdeldjalil Djehaf ${ }^{3}$, Sid Ahmed Zidi', \\ Riyadh Bouddou ${ }^{5}$ \\ ${ }^{1,2,4}$ ICEPS Laboratory, Department of Electrotechnics, Djillali Liabes University of Sidi Bel-Abbes, Algeria \\ ${ }^{3,5}$ IRECOM Laboratory, Department of Electrotechnics, Djillali Liabes University of Sidi Bel-Abbes, Algeria
}

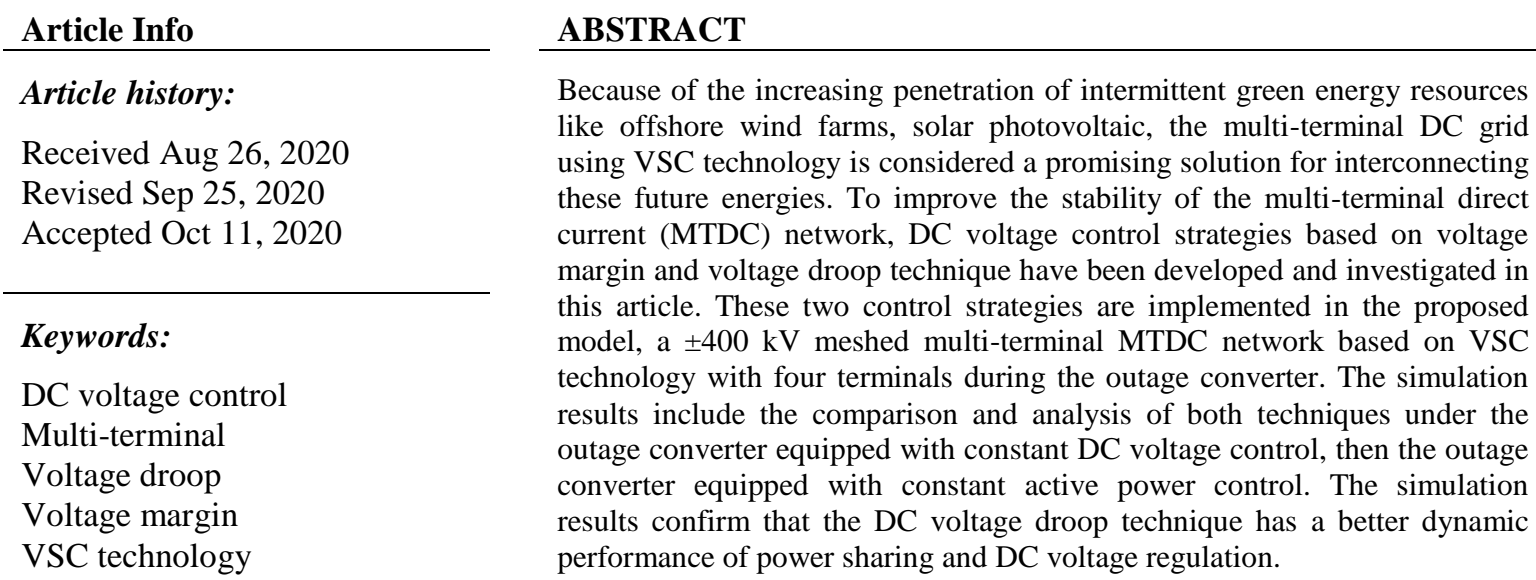

This is an open access article under the $\underline{C C B Y-S A}$ license.

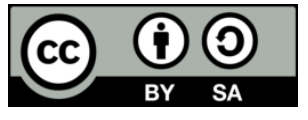

Corresponding Author:

Moussa Belgacem

Department of Electrotechnics

Djillali Liabes University of Sidi Bel-Abbes, Algeria

Email: moussa.be193@gmail.com

\section{INTRODUCTION}

Nowadays, with the fast increase in demand for electricity in the world, the electrical network needs to be improved to facilitate exchanges and connect renewable energies such as offshore wind farms, solar photovoltaic. High voltage DC (HVDC) technology is an important technology in the interconnection of renewable energies because it has several advantages compared with a high voltage AC (HVAC) technology, (1) Bulk transmission of power over long distances, (2) Interconnection of asynchronous networks, (3) It is the only possibility to transport electricity in underground or submarine cables over distances of more than about $100 \mathrm{~km}[1-3]$.

Most of the HVDC links in operation today are point-to-point (PTP) with two points of connection with the AC networks, which use either LCC or VSC technology for the converters [4-6]. However, it is envisaged that a DC network consists of more than two converters station called multi-terminal direct current (MTDC) networks. The classical technology LCC-HVDC is challenging to build the MTDC network because it needs reversing the line's polarity to change the power flow. Hence, another technology called VSC-HVDC is preferred to build MTDC network because it doesn't reverse their polarity but only their current, seem to be more suitable and easier to control [7]. However, the MTDC network can adopt LCC technology. In the literature $[8,9]$, a multi-terminal MTDC network based on the LCC converter was presented and developed. 
VSC-MTDC control based on decoupled vector control is composed of outer controllers and inner current controller [6]. To achieve the MTDC grid's flexibility, different DC voltage control strategies were developed, the master-slave technique, voltage margin technique, and voltage droop technique. For the master-slave technique, as a natural extension of the control of PTP VSC-HVDC, only one converter as known (slack bus or master) within the MTDC network could regulate the DC voltage while the rest converters would control the active power transfer and once the master converter fails due to a fault, the MTDC network will be unstable in consequence of having no converter to control DC voltage [10, 11]. For the voltage margin technique, the VSCs converters can be changed control mode between DC voltage and active power, only one slack bus at each time [12]. For the voltage droop technique, more than one converter participates in DC voltage regulation of the MTDC network simultaneously [13-15].

To solve the problem of the master-slave technique when the outage of the slack bus converter, DC voltage control strategies based on voltage margin and voltage droop techniques have been developed in this article. These two techniques are implemented in the proposed model, a $\pm 400 \mathrm{kV}$ meshed multi-terminal MTDC network based on VSC technology with four terminals [16, 17]. The voltage margin technique is automatically implemented to improve communication between the converters $[12,18]$. The droop technique or decentralized technique developed in this article is a technique that allows the power sharing between different converters without communications [19]. To verify the performance of the two techniques, an outage of a VSC converter equipped with constant DC voltage control, then an outage of a VSC converter equipped with constant active power control are investigated.

The remainder of this paper is structured as: The characteristics of VSC station for interconnecting of MTDC network with different power electrical are shown in section 2. Section 3 presents different DC voltage techniques especially, master-slave, voltage margin and voltage droop techniques. Then, the developed VSC-MTDC model with four terminals using PSCAD/EMTDC is described in section 4. Section 5 reports the simulation results and compares the performance of both techniques from different scenarios. And finally, section 6 draws the conclusions of this paper.

\section{CHARACTERISTICS OF VSC-MTDC NETWORK}

\subsection{VSC station in MTDC network}

The VSC-MTDC network is composed of VSC converters and high voltage DC transmission (cables or lines). The main diagram of a single VSC station is shown in Figure 1. This station consists of the principal component called VSC converter, which connected to the phase reactor. The phase reactor is connected to the AC network at the so-called point of the common coupling (PCC) through the transformer [6].

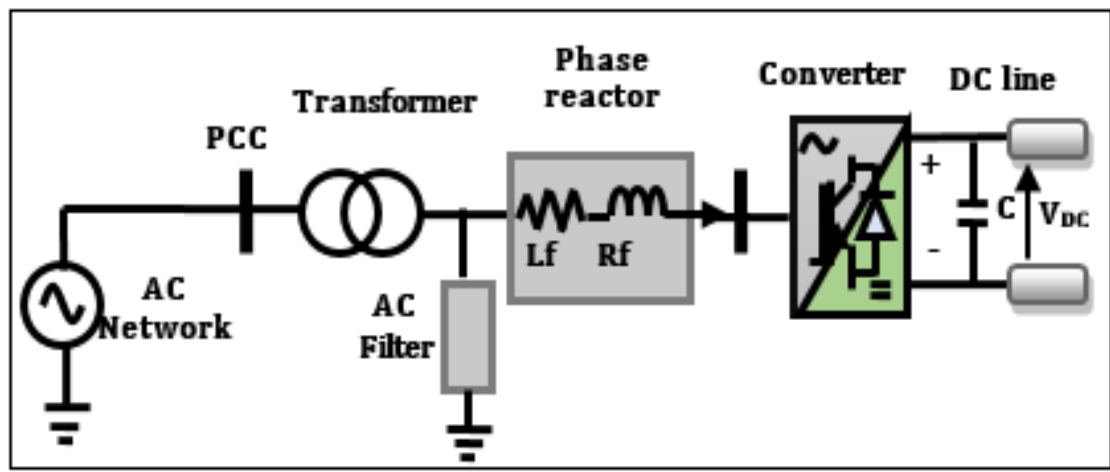

Figure 1. Main diagram of a single VSC station

\subsection{MTDC network for interconnecting with power electrical}

As shown in Figure 2, the MTDC network based on VSC converter is usually used to interconnect with different conventional power networks such as offshore wind farms and photovoltaic power stations [20]. In [21], a wind generation system type 4 was integrated into the AC grid through the VSC-HVDC link. The VSC converter is required for the construction of the MTDC network because it can offer several advantages [6]:

- $\quad$ It has the capability of independent control of both active and reactive powers.

- $\quad$ The DC link can be connected to a weak or passive AC network providing frequency control.

- $\quad$ High reduction of the harmonic content and elimination. 


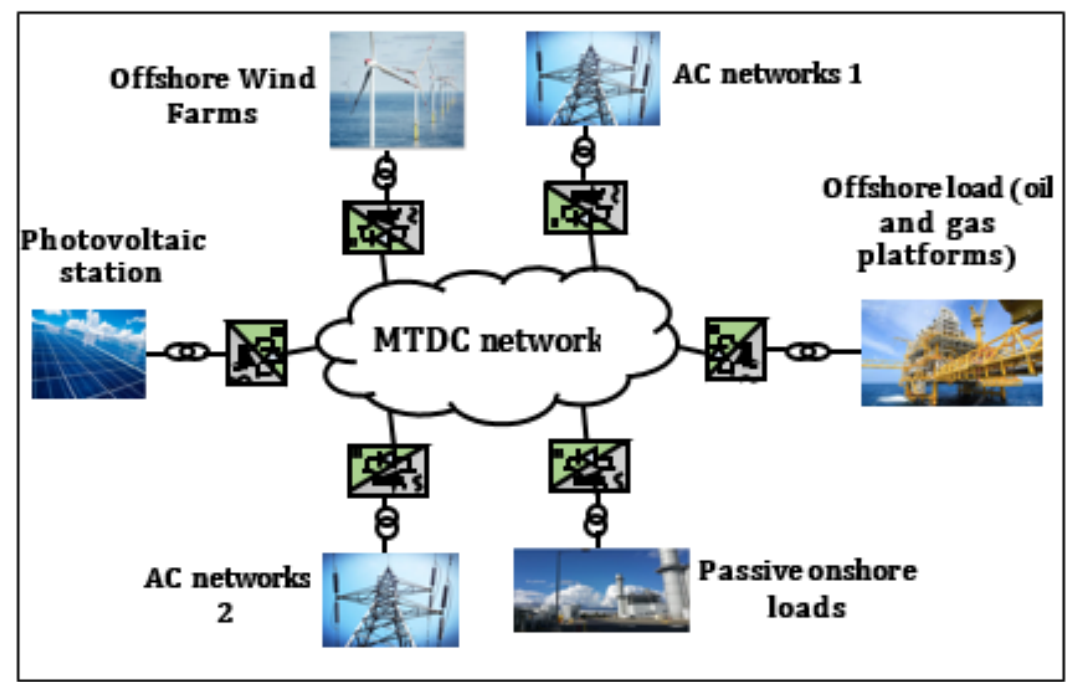

Figure 2. MTDC network interconnected with several electrical powers

\section{DC VOLTAGE CONTROL STRATEGIES OF VSC-MTDC NETWORK}

Considering in MTDC network each two-level VSC converter connected to the AC grid, the main control of the MTDC network is categorized into two different layers of controllers the VSC terminal controller and master controllers. The control strategy used at each converter is based on the vector control method in the terminal controller. Figure 3 shows the general structure of the VSC converter using the d-q vector control technique. In this technique, the AC voltages and currents measured at PCC are transformed into q-d reference axis using Clarke/Park transformations [22]. The synchronization of the VSC converter with the AC grid is performed by a phase-locked loop (PLL), which produces frequency and phase angle ( $\theta)$ [23]. The designed control of this technique is divided into an inner current controller and outer controllers. The inner current controller is composed of two controllers, respectively, for $\mathrm{d}$ and $\mathrm{q}$ axis current control. The reference values of direct current $\left(\mathrm{I}^{*}{ }_{\mathrm{s}-\mathrm{d}}\right)$ and reactive current $\left(\mathrm{I}_{\mathrm{s}-\mathrm{q}}{ }^{*}\right)$ are garnered from the outer controllers, where DC voltage control or active power control are designed to derive $\mathrm{I}_{\text {s-d }}^{*}$ and $\mathrm{AC}$ voltage control, or reactive power control are designed to derive $\mathrm{I}_{\mathrm{s} \text {-q }}^{*}$. The instantaneous active and reactive currents $\left(\mathrm{I}_{\mathrm{s}-\mathrm{d}}\right.$ and $\left.\mathrm{I}_{\mathrm{s}-\mathrm{q}}\right)$ are controlled by generating the reference voltages $\mathrm{V}^{*}{ }_{\mathrm{s}-\mathrm{d}}$ and $\mathrm{V}_{\mathrm{s} \text {-q }}^{*}$, which are re-transformed to the three phases (abc) frame and served into input signal to the PWM of the VSC converter.

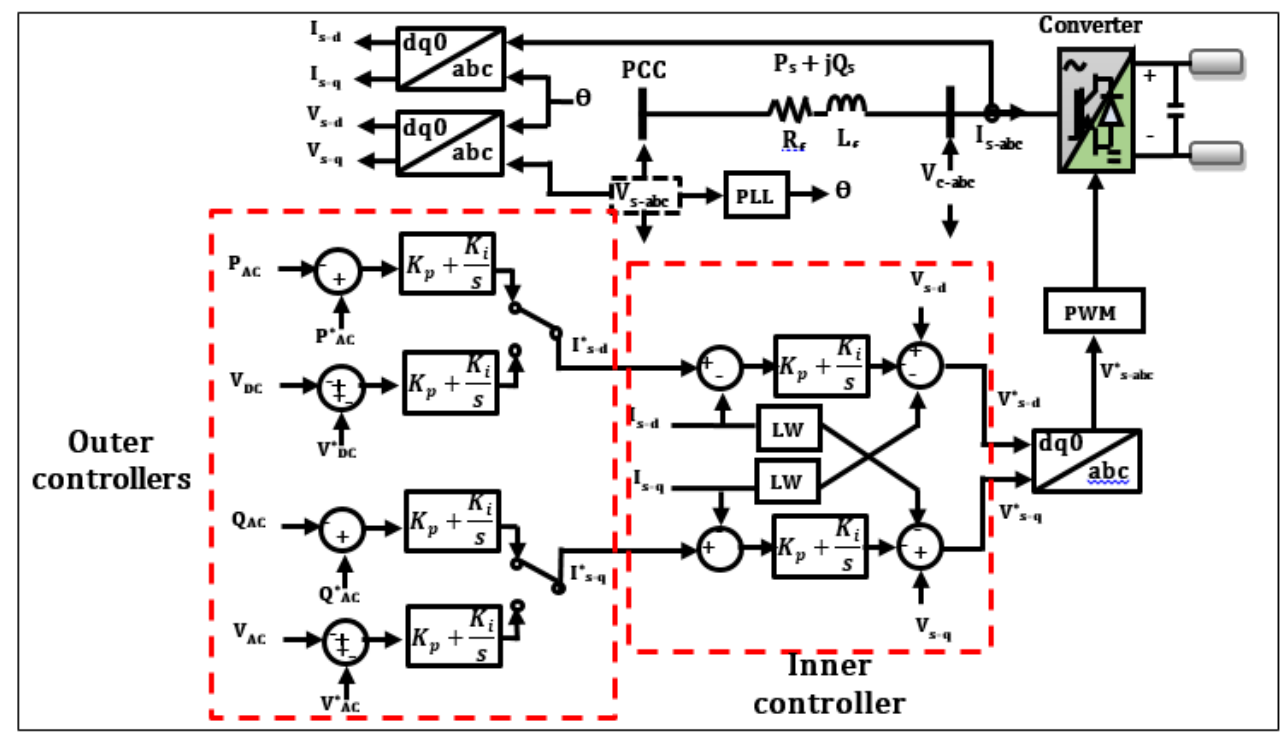

Figure 3. General structure of VSC converter using d-q vector control 
The dynamics of the VSC terminal in Figure 3 can be expressed in the q-d reference axis as,

$$
\begin{aligned}
& \frac{d I_{s-d}}{d t}=-\frac{R_{f}}{L_{f}} I_{s-d}-\frac{1}{L_{f}}\left(V_{s-d}-V_{c-d}\right)+j \omega I_{s-q} \\
& \frac{d I_{s-q}}{d t}=-\frac{R_{f}}{L_{f}} I_{s-q}-\frac{1}{L_{f}}\left(V_{s-q}-V_{c-q}\right)-j \omega I_{s-d}
\end{aligned}
$$

In the master controllers, three control strategies based on DC voltage control: master-slave, voltage margin, and voltage droop techniques are developed in a multi-terminal DC network.

\subsection{Master-slave technique}

Generally, the master-slave technique (coordinated control) is used for point-to-point and multiterminal HVDC (MTDC) [24]. In this technique, one converter called (master) is designed in constant DC voltage control mode, while the remaining converters called (slaves) are described in constant active power control mode. The function of the master terminal is to maintain the DC voltage at the reference value. This converter will operate like a battery, which means that it will deliver or consume the active power to ensure the power balance of the MTDC network [25]. Figure 4(a) shows the P-V characteristics of a PTP-HVDC system, one converter (master) in orange, and another converter (slave) in blue. The master maintains a constant DC voltage, regardless of its power, while the slave injects constant power, regardless of its voltage. The difference between DC voltage measured $\left(\mathrm{V}_{\mathrm{DC}}\right)$ and $\mathrm{DC}$ voltage of reference $\left(\mathrm{V}^{*}{ }_{\mathrm{DC}}\right)$ is processed through a PI regulator to produce the desired direct current reference $\mathrm{I}^{*}{ }_{\mathrm{s}-\mathrm{d}}$, the active power controller works with a similar principle as presented in Figure 4(b). The existing MTDC network using the master-slave technique in China was built in 2014 as a known Zhoushan project with five converter terminals [26]. The disadvantage of this technique is the instability of the MTDC network when a master converter fails [11]. To solve the problem of the disconnection of the master converter, two techniques called voltage margin, and voltage droop technique are developed and compared in this article.

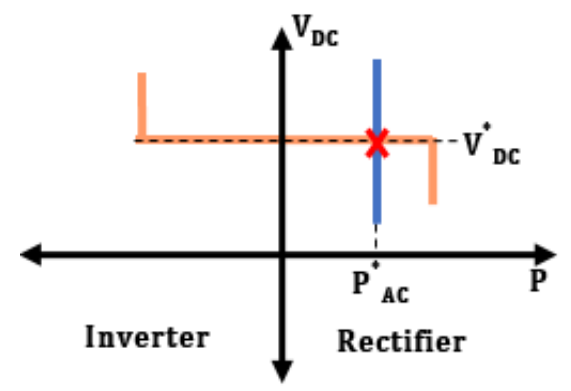

(a)

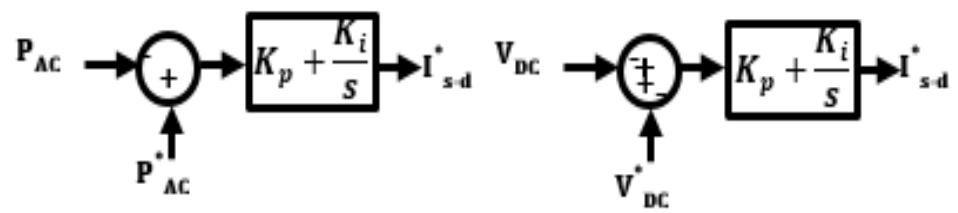

Active power control

(b)

Figure 4. Master-slave technique applied to PTP-HVDC system, (a) DC voltage versus active power characteristics, (b) basic scheme of the method

\subsection{Voltage margin technique}

The voltage margin technique was first proposed for the VSC-HVDC network in [27]. This technique is a modification of the master-slave technique in which DC voltage and power control modes are combined, at each time, only one slack bus $[12,18]$. As shown in Figure 5(a), the P-V characteristics of a PTP-HVDC system, the first converter in orange, and the second converter in blue. The first converter adopts DC voltage control mode with its reference value $\mathrm{V}^{*}{ }_{\mathrm{DC} 1}$, while this converter works with its limits of active power. When the limits of converter 1 are reached, the control mode of this converter will be switched to constant power control. Under this event, the control mode of converter 2 will be switched from constant power to DC voltage control mode and operate at the new set value $\mathrm{V}^{*}{ }_{\mathrm{DC} 2}$. The difference between $\mathrm{V}^{*}{ }_{\mathrm{DC} 1}$ and $\mathrm{V}^{*}{ }_{\text {DC2 }}$ is called voltage margin. Generally, the voltage margin technique may be implemented in more than one VSC converter in MTDC networks. Figure 5(b) shows the implementation diagram of the technique in the VSC converter used in this paper. 


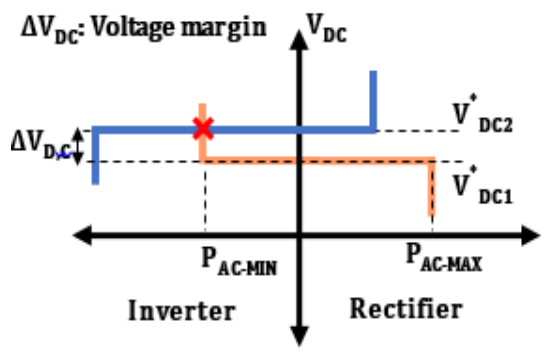

(a)

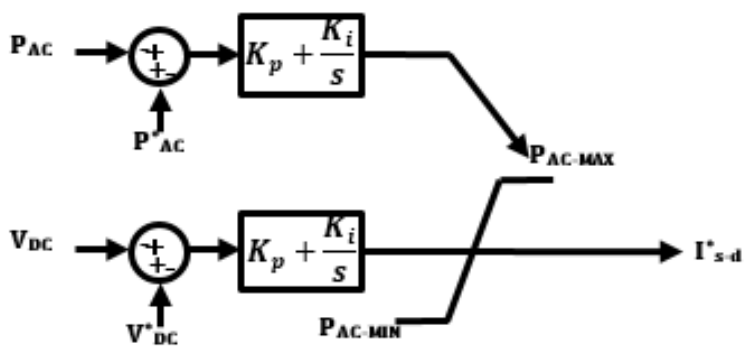

(b)

Figure 5. Voltage margin technique applied to PTP-HVDC system, (a) DC voltage versus active power characteristics, (b) Basic scheme of the technique

\subsection{Voltage droop technique}

The stability of the MTDC network can be improved by acting more than one converter for DC voltage regulation. The voltage droop technique works similarly to the one implemented in the AC network, where the consumption dependent frequency variation. In the DC network, the droop technique employs the droop mechanism to control the DC voltage by adjusting the converter power injections [14]. In the PTP VSC-HVDC network, only one converter is responsible for the regulation of DC voltage. However, in the MTDC network, more converter will be needed to control DC voltage. Thus, the droop technique has a better performance and flexibility between all converters for controlling the DC voltage [15, 28]. The DC voltage versus power characteristics of the droop technique is shown in Figure 6(a). This technique can be seen as a proportional control in which the droop coefficient $\rho_{V_{D C}}$ is equal to the inverse of the characteristic curve slope. The difference between the reference value of active power $P_{A C}^{*}$ and the actual power $P_{A C}$ produces corrective droop signaled by the droop coefficient $\rho_{V_{D C}}$. Equation (3) expresses the relation between the DC voltage deviation and the power sharing of the VSC converter equipped with a droop technique. Figure 6(b) shows the implementation diagram of the technique in the VSC converter used in this paper.

$$
P_{A C}=P_{A C}^{*}-\frac{1}{\rho_{V_{D C}}}\left(\mathrm{~V}_{D C}^{*}-V_{D C}\right)
$$

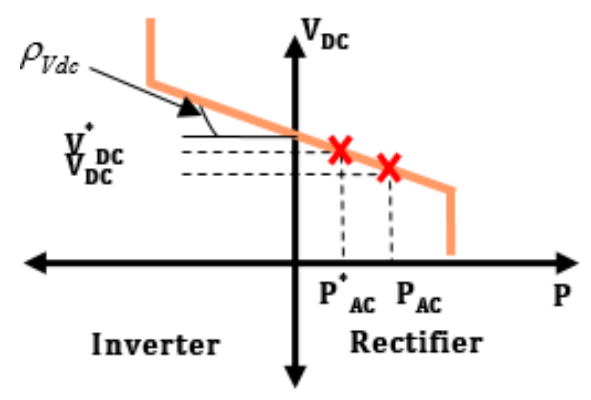

(a)

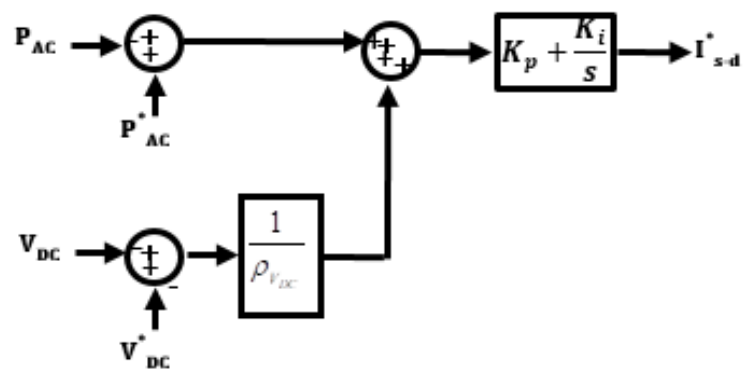

(b)

Figure 6. Voltage droop technique applied to PTP-HVDC system, (a) DC voltage versus active power characteristics, (b) basic scheme of the technique

\section{MTDC SYSTEM MODEL}

A four-terminal meshed MTDC network tested in this paper is presented in Figure 7. It consists of four converters based on VSC technology, which are connected with four active AC networks. The main objective of this paper is to verify the reliability of both voltage margin and voltage droop techniques under lost any converter station. The simulation results are verified by PSCAD/EMTDC software. The different scenarios studied and control strategies used in this paper are shown in Table 1. The parameters and rating values of the MTDC network are presented in Table 2. 


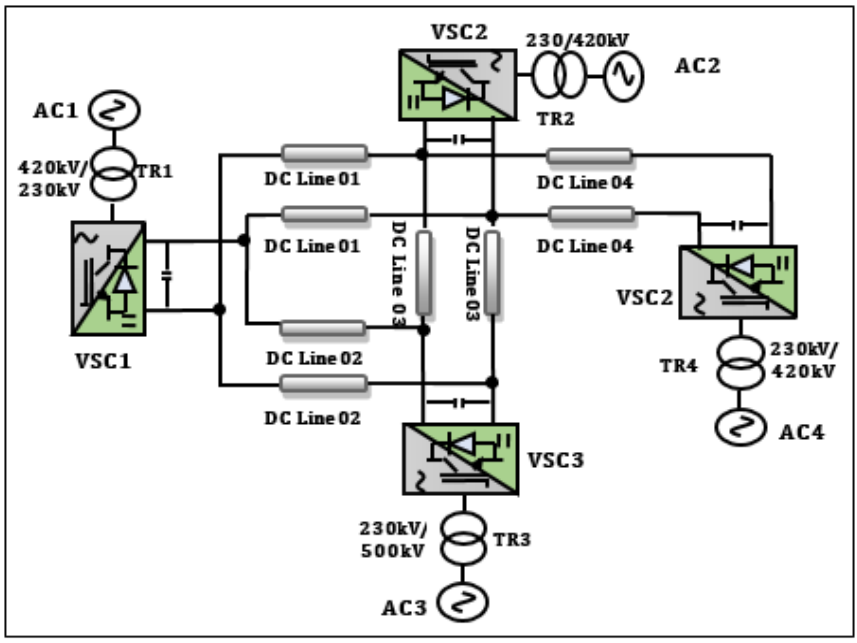

Figure 7. VSC-MTDC model with four terminals

Table 1. Different scenarios studied and control strategies

\begin{tabular}{ccccc}
\hline Scenarios & VSC1 & VSC2 & VSC3 & VSC4 \\
\hline I-VSC1 outage & DC voltage margin & DC voltage margin & Constant power & Constant power \\
II-VSC1 outage & DC voltage droop & DC voltage droop & Constant power & Constant power \\
III-VSC4 outage & DC voltage margin & DC voltage margin & Constant power & Constant power \\
IV-VSC4 outage & DC voltage droop & DC voltage droop & Constant power & Constant power \\
\hline
\end{tabular}

Table 2. MTDC grid parameters and droop coefficients

\begin{tabular}{ccc}
\hline Symbol & Parameter system & Value \\
\hline $\mathrm{S}_{\mathrm{VSC}}$ & VSC rated power & $1500 \mathrm{MVA}$ \\
$\mathrm{S}_{\mathrm{b}}$ & AC network rated power & $100 \mathrm{MVA}$ \\
$\mathrm{V}_{\mathrm{DC}}$ & VSC nominal DC voltage & $400 \mathrm{kV}$ \\
$\mathrm{V}_{\mathrm{s}-\mathrm{c}}$ & VSC nominal AC voltage & $230 \mathrm{kV}$ \\
$\mathrm{Z}_{\mathrm{AC}}$ & AC networks impedance & $26.45 \Omega$ \\
$\Omega_{\mathrm{AC}}$ & AC networks impedance phase angle & $80^{\circ}$ \\
$\mathrm{S}_{\mathrm{CR}}$ & Short Circuit Ratio & 2.5 \\
$\mathrm{f}_{\mathrm{AC} 1}$ & AC frequency (VSC1) & $60 \mathrm{~Hz}$ \\
$\mathrm{f}_{\mathrm{AC} 2}$ & AC frequency (VSC2, VSC3, VSC4) & $50 \mathrm{~Hz}$ \\
$\mathrm{f}_{\mathrm{SW}}$ & Switching frequency & $1980 \mathrm{~Hz}$ \\
$\mathrm{C}$ & DC capacitor & $300 \mu \mathrm{F}$ \\
$\mathrm{R}_{\mathrm{l}}$ & DC line resistance & $7 \Omega$ \\
$\mathrm{L}_{\mathrm{l}}$ & DC line inductance & $0.5968 \mathrm{H}$ \\
$\mathrm{C}_{1}$ & DC line capacitance & $26 \mu \mathrm{F}$ \\
$\rho_{\mathrm{VDC}}$ & Droop coefficient & $0.02 \mathrm{kv} / \mathrm{MW}$ \\
$\mathrm{K}_{\mathrm{p}-\mathrm{DC}}$ & Proportional gain of outer control loop (DC voltage) & 0.05 \\
$\mathrm{~T}_{\mathrm{i}-\mathrm{DC}}$ & Time constant of outer control loop (DC voltage) & 3 \\
$\mathrm{~K}_{\mathrm{p}-\mathrm{AC}}$ & Proportional gain of outer control loop (AC voltage) & 10 \\
$\mathrm{~T}_{\mathrm{i}-\mathrm{AC}}$ & Time constant of outer control loop (AC voltage) & 0.0012 \\
$\mathrm{~K}_{\mathrm{p}}$ & Proportional gain of inner control loop & 65 \\
$\mathrm{~T}_{\mathrm{i}}$ & Time constant of inner control loop & 0.00001 \\
\hline & &
\end{tabular}

\section{SIMULATION RESULTS}

5.1. Scenario studied 1: VSC1 outage under voltage margin technique

In this case, the DC voltage margin technique is implemented, VSC1 converter (master) operates in a DC voltage control mode at $400 \mathrm{kV}$ while VSC2, VSC3, and VSC4 (slaves) operate in a constant power control mode. After the outage of the VSC1 converter, the second converter VSC2 change mode control from constant power control to DC voltage control mode at a new set value $410 \mathrm{kV}$ while the remaining converters operate in a constant power control mode. The outage of the VSC1 converter is considered at $2 \mathrm{~s}$. The Table 3 shows a set value of the MTDC network under voltage margin technique.

Looking at Figure 8(a), it is apparent that when VSC1 equipped with DC voltage control (first master converter) is lost, the active and reactive powers of VSC1 decrease to 0. Therefore, the VSC2 is transformed into the master station and changed from constant power control to DC voltage control. 
Following the outage, it can be seen that the instability of the active power of VSC2 (second master converter) when the control mode is changed then increases to $217 \mathrm{MW}$ to compensate for the unbalanced power caused by the outage of VSC1 converter. The outage converter does not affect the power transit through the VSC4 converter. We can also observe after the outage, instability of the active power of VSC3 then returns to its normal state.

Figure 8(b) shows the DC voltage response of the converters following the outage of the VSC1 converter. During the change in their control mode between VSC1 and VSC2, the DC voltage of VSC2 becomes unstable and then increases to a new set value of $410 \mathrm{kV}$. Hence, the DC voltage of VSC3 and VSC4 become unstable when the control mode is changed between VSC1 and VSC2.

Table 3. Different set values of MTDC network under voltage margin technique

\begin{tabular}{cccccc}
\hline & Converter & VSC1 & VSC2 & VSC3 & VSC4 \\
\hline Before VSC1 outage & $\mathrm{V}^{*}{ }_{\mathrm{DC}}$ & $400 \mathrm{kV}$ & - & - & - \\
& $\mathrm{P}^{*}{ }_{\mathrm{AC}}$ & - & $100 \mathrm{MW}$ & $-300 \mathrm{MW}$ & $100 \mathrm{MW}$ \\
After VSC1 outage & $\mathrm{V}^{*}{ }_{\mathrm{DC}}$ & - & $410 \mathrm{kV}$ & - & - \\
& $\mathrm{P}^{*}{ }_{\mathrm{AC}}$ & - & - & $-300 \mathrm{MW}$ & $100 \mathrm{MW}$ \\
\hline
\end{tabular}

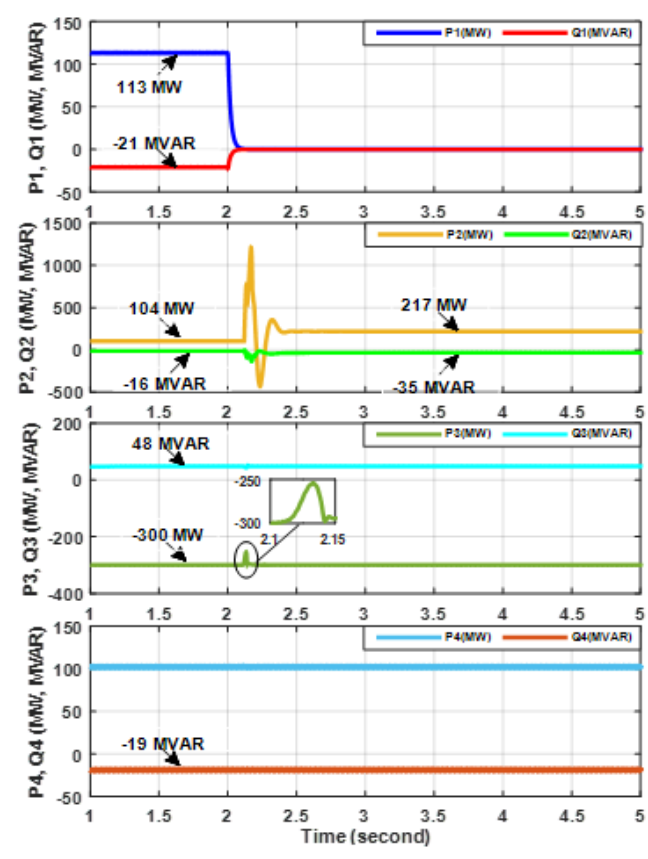

(a)
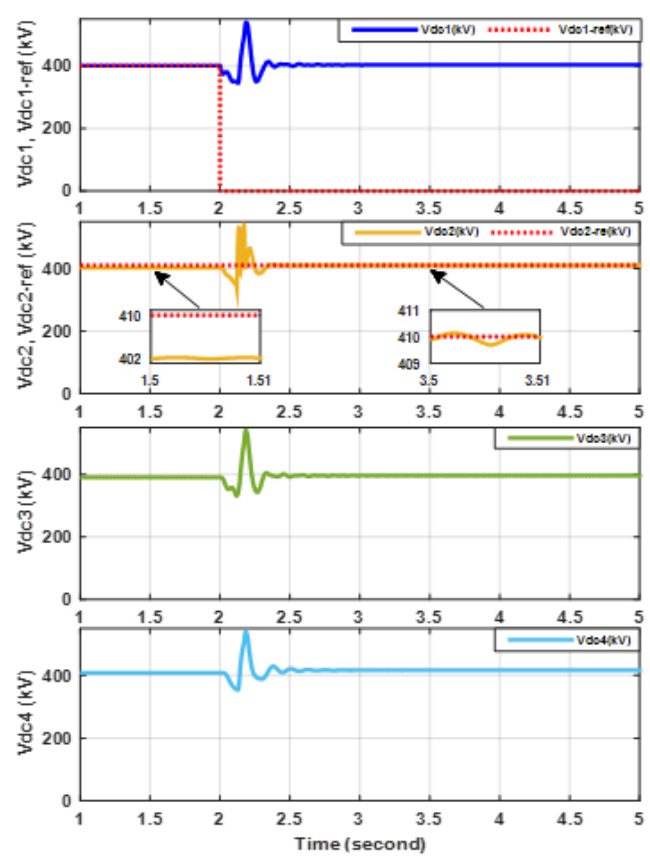

(b)

Figure 8. Dynamic response of MTDC network with voltage margin technique under the outage of VSC1, (a) power transfer, (b) DC voltage

\subsection{Scenario studied 2: VSC1 outage under voltage droop technique}

DC voltage droop control is implemented in this case, VSC1 and VSC2 adopt voltage droop technique while VSC3 and VSC4 adopt constant power control. The outage of the VSC1 converter is considered at $2 \mathrm{~s}$. The Table 4 shows the set values of the MTDC network under voltage droop technique.

Figure 9(a) shows the converters' response of the active and reactive powers following the outage of the VSC1 converter under voltage droop technique. In the steady state both VSC1 and VSC2 converters equipped with droop control act as rectifiers importing about $120 \mathrm{MW}$ and $100 \mathrm{MW}$, respectively, into the MTDC network, while those VSC3 and VSC4 operate at constant power control, VSC3 works as inverter carrying around $-300 \mathrm{MW}$ and VSC4 act as rectifier importing about $100 \mathrm{MW}$. After the outage, it can be seen that the VSC2 converter increases its active power to $218 \mathrm{MW}$ to compensate for the unbalanced power caused by the outage of the VSC1 converter. We also observe that the outage converter does not affect the power transit through both VSC3 and VSC4 converters. Therefore, the voltage droop method has better performance under the outage converter compared with the voltage margin method. It can be seen from 
Figure 9(b) that the change of active power of VSC2 causes DC voltage deviation, which is reduced from 396 to $388 \mathrm{kV}$. We also observe that the DC voltage of VSC3 is reduced from $384 \mathrm{kV}$ to $372 \mathrm{kV}$, and VSC4 is reduced from $402 \mathrm{kV}$ to $395 \mathrm{kV}$.

Table 4. Different set values of MTDC network under voltage droop technique

\begin{tabular}{ccccc}
\hline Converter & VSC1 & VSC2 & VSC3 & VSC4 \\
\hline $\mathrm{V}^{*}{ }_{\mathrm{DC}}$ & $400 \mathrm{kV}$ & $400 \mathrm{kV}$ & $100 \mathrm{MW}$ & $100 \mathrm{MW}$ \\
$\mathrm{P}^{*}{ }_{\mathrm{AC}}$ & - & $100 \mathrm{MW}$ & $-300 \mathrm{MW}$ & $100 \mathrm{MW}$ \\
$\rho_{\mathrm{VDC}}$ & $0.02 \mathrm{kV} / \mathrm{MW}$ & $0.02 \mathrm{kV} / \mathrm{MW}$ & - & - \\
\hline
\end{tabular}
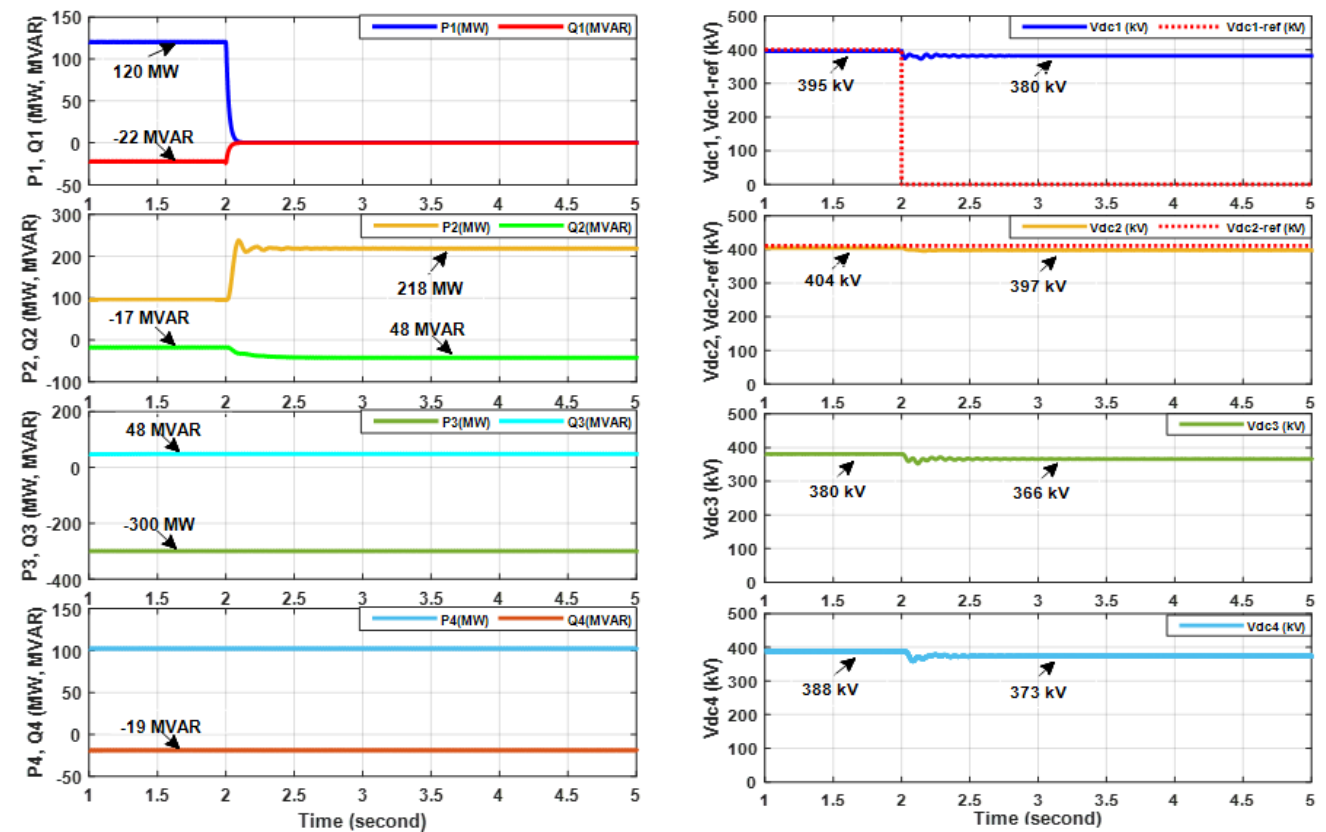

(a)

(b)

Figure 9. Dynamic response of MTDC network with voltage droop technique under the outage of VSC1,

(a) power transfer; (b) DC voltage

\subsection{Scenario studied 3: VSC4 outage under voltage margin technique}

Scenario 3 is set up to verify the control performance of the voltage margin technique when the outage of the VSC4 converter adopts constant power control. In this case, VSC1 adopts DC voltage control with the reference value $400 \mathrm{kV}$ while VSC2, VSC3, and VSC4 adopt constant power control with the reference values $100 \mathrm{MW},-300 \mathrm{MW}$ and $100 \mathrm{MW}$ respectively. The outage of the VSC4 converter considered at $2 \mathrm{~s}$.

In this scenario, an outage converter equipped with constant power control (VSC4), which injects $100 \mathrm{MW}$, is considered at $2 \mathrm{~s}$. As shown in Figure 10(a), the active power response of the MTDC network is presented. After the outage, the VSC1 converter (slack bus) increases its active power to 212 MW to compensate for the unbalanced power caused by the outage of the VSC4 converter. We also observe that the active and reactive powers of VSC2 and VSC3 are unchanged during the outage. The evolution of the DC voltage at the MTDC grid is illustrated in Figure 10(b). We can see, the outage of VSC4 gives some transients in the DC voltage of the three converters (VSC2, VSC3, and VSC4) then decreases to the new values. The DC voltage of the master converter (VSC1) remains at the previous level with slight fluctuation.

\subsection{Scenario studied 4: VSC4 outage under voltage droop technique}

DC voltage droop technique is implemented in scenario 4 during the outage of the VSC4 converter, which adopts constant power control. The outage of the VSC4 converter considered at 2 s. From Figure 11(a) above, we can see that after the outage converter, both VSC1 and VSC2 converters implemented on droop control mode participate in sharing the unbalanced power caused by the outage of VSC4 converter. The active power of VSC1 from $120 \mathrm{MW}$ increased to $157 \mathrm{MW}$, and the active power of VSC2 from $100 \mathrm{MW}$ 
increased to $157 \mathrm{MW}$. We also observe that the active and reactive powers of VSC3 are unchanged during the outage. It can be seen in Figure 11(b). The outage converter causes a DC voltage deviation of VSC1 and VSC2 converters. The DC voltage of VSC1 is reduced from $394 \mathrm{kV}$ to $392 \mathrm{kV}$, and VSC2 is reduced from $396 \mathrm{kV}$ to $392 \mathrm{kV}$.

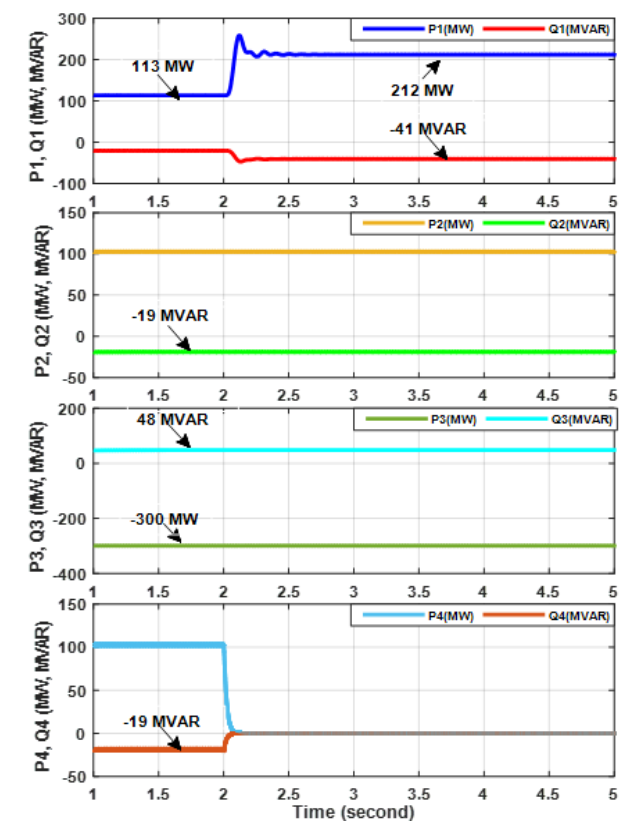

(a)

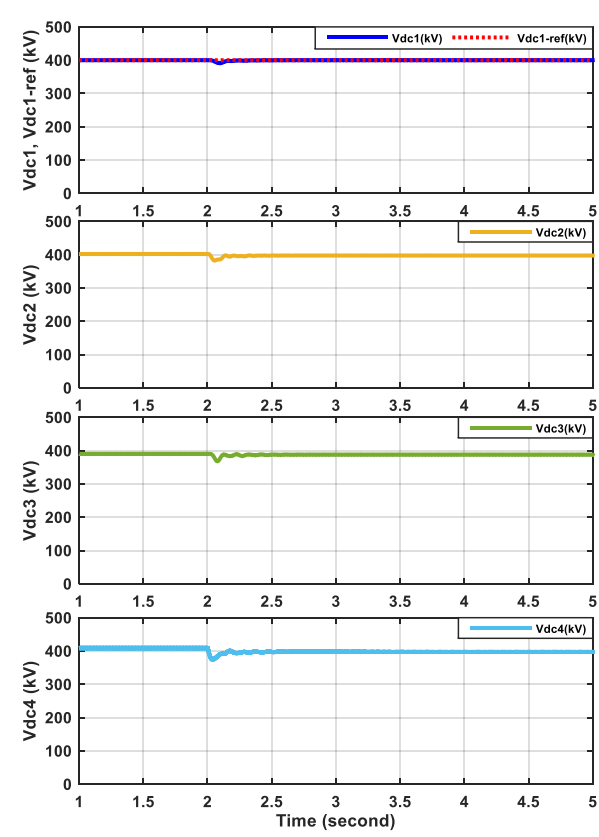

(b)

Figure 10. Dynamic response of MTDC network with voltage margin technique under the outage of VSC4; (a) power transfer; (b) DC voltage

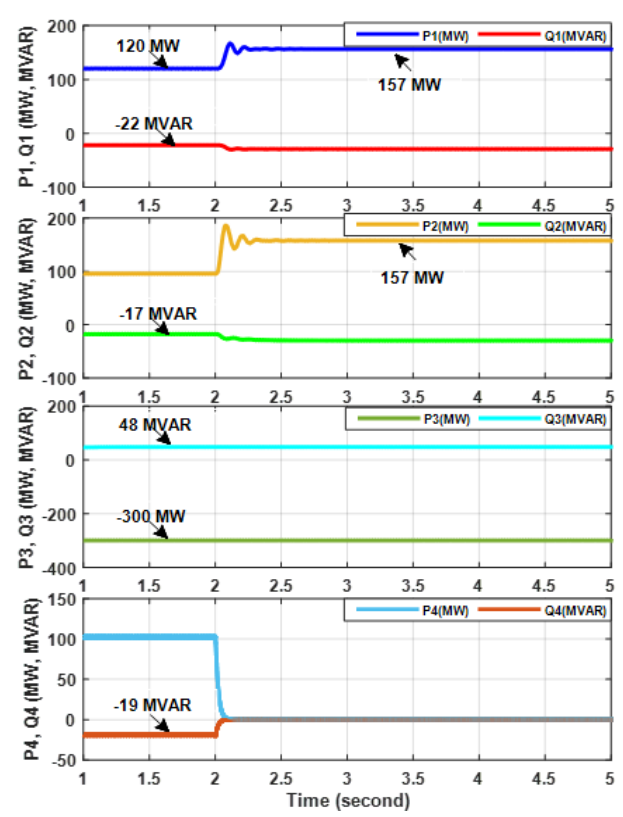

(a)

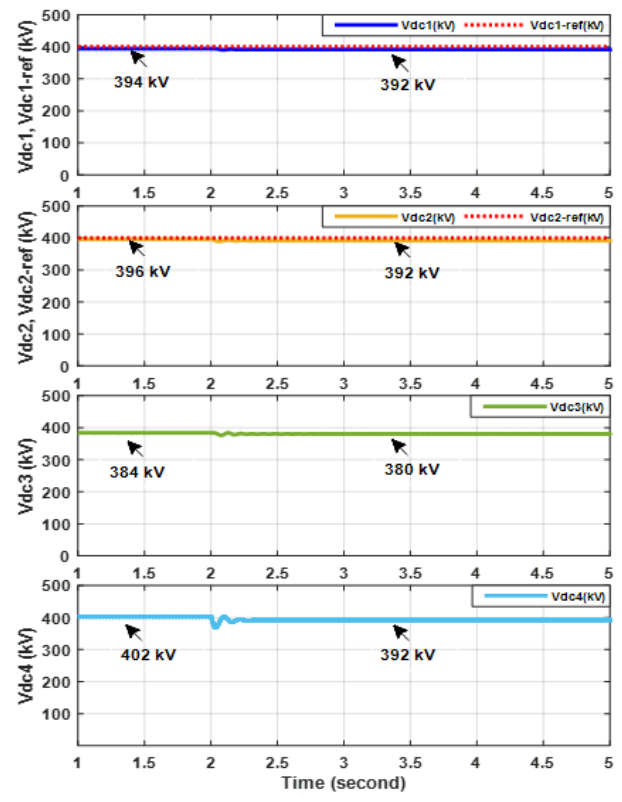

(b)

Figure 11. Dynamic response of MTDC network with voltage droop technique under the outage of VSC4, (a) power transfer; (b) DC voltage 


\section{CONCLUSION}

In this article, a multi-terminal based on the VSC-HVDC network with four terminals was investigated and its performance during the outage converter. Two DC voltage techniques are known as voltage margin and voltage droop were developed and studied using PSCAD/EMTDC program. The outage converter equipped with DC voltage and constant power control is considered in this work. The main conclusion of the simulation results is as: i) When the outage of the VSC converter equipped with DC voltage control, using the voltage margin technique, the MTDC network may be unstable after the outage. During the change of their role between both converters, the DC voltage of the DC grid becomes unstable. On the other hand, In the droop technique, the MTDC network has a better dynamic response and best DC voltage control and active power-sharing; ii) When the outage of the VSC converter equipped with active power control, the MTDC network responds quickly with voltage margin technique and only the slack bus converter, which can compensate for the lack of active power caused by the outage converter. In the droop technique, more than one converter participates in the DC voltage regulation and power sharing of the MTDC network. However, the main problem of this technique includes a DC voltage deviation.

\section{REFERENCES}

[1] J. Sun, M. Li, Z. Zhang, T. Xu, J. He, H. Wang, and G. Li, "Renewable energy transmission by HVDC across the continent: system challenges and opportunities," CSEE Journal of Power and Energy Systems, vol. 3, no. 4, pp. 1-11, 2017.

[2] ABB, "HVDC Light $\circledR$ It's Time to Connect," POW-0038, 2012.

[3] M. P. Bahrman, B. K. Johnson, "The ABCs of HVDC transmission technologies," IEEE Power and Energy Magazine, vol. 5, no. 2, pp. 32-44, 2007.

[4] O. E. Oni, I. E. Davidson, and K. N. I. Mbangula, "A review of LCC-HVDC and VSC-HVDC technologies and applications," in 2016 IEEE 16th International Conference on Environment and Electrical Engineering (EEEIC), Florence, 2016, pp. 1-7.

[5] J. Khazaei, P. Idowu, A. Asrari, A. B. Shafaye, and L. Piyasinghe, "Review of HVDC control in weak AC grids," Electric Power Systems Research, vol. 162, pp. 194-206, 2018.

[6] A. Korompili, Q. Wu, H. Zhao, "Review of VSC HVDC connection for offshore wind power integration," Renewable and Sustainable Energy Reviews, vol. 59, pp. 1405-1414, 2016.

[7] D. V. Hertem and M. Ghandhari, "Multi-terminal VSC HVDC for the European supergrid: obstacles," Renewable \& Sustainable Energy Reviews, no. 14, no. 9, pp. 3156-3163, 2011.

[8] R. L. Vasquez-Arnez, J. A. Jardini, and M. T. Bassini, "Dynamic performance of line commutated converter based multi-terminal HVDC systems," Przeglad Elektrotechniczny, vol. 91, pp. 247-253, 2015.

[9] O. E. Oni, Andrew G. Swanson, R. P. Carpanen, "Impact of LCC-HVDC multi-terminal on generator rotor angle stability," International journal of electrical and computer engineering (IJECE), vol. 10, no. 1, pp. 22-34, 2020.

[10] F. D. Bianchi, J. L. Domiınguez-Garcia, and O. Gomis-Bellmunt, "Control of multi-terminal HVDC networks towards wind power integration: A review," Renewable and Sustainable Energy Reviews, vol. 55, pp. 1055-1068, 2016

[11] N. Yousefpoor, S. Kim, and S. Bhattacharya, "Multi-terminal DC grid control under loss of terminal station," in 2014 IEEE Energy Conversion Congress and Exposition (ECCE), Pittsburgh, PA, 2014, pp. 744-749.

[12] M. Belgacem, M. Khatir, M. A. Djehaf, R. Bouddou and S. A. Zidi, "Modeling and Control of Multi-Terminal Direct Current with Voltage Margin Control Strategy," 2019 4th International Conference on Power Electronics and their Applications (ICPEA), Elazig, Turkey, 2019, pp. 1-6.

[13] K. Rouzbehi, A. Miranian, A. Luna, and P. Rodriguez, "A Novel approach for voltage control of multi-terminal DC grids with offshore wind farms," 2013 IEEE ECCE Asia Downunder, Melbourne, VIC, 2013, pp. 965-970.

[14] A. S. Abdel-Khalik, A. M. Massoud, A. A. Elserougi and S. Ahmed, "Optimum power transmission based droop control design for multi-terminal HVDC of offshore wind farms," in IEEE Transactions on Power Systems, vol. 28, no. 3, pp. 3401-3409, 2013.

[15] M. Belgacem, M. Khatir, M. A. Djehaf, R. Bouddou and F. Behamida, "Analysis and impacts of implementing droop control in multi-terminal VSC-HVDC under the steady state and transient stability," 2020 International Conference on Electrical and Information Technologies (ICEIT), Rabat, Morocco, 2020, pp. 1-6.

[16] H. Hu, Y. Liu, R. Long, T. Tan, Y. Meng, J. Zhang, et al., "PSCAD/EMTDC based modeling and simulation of three-terminal VSC-HVDC system," in International Conference on Civil, Architectural and Hydraulic Engineering, 2016.

[17] G. P. Adam, S. J. Finney, B. W. Williams, K. Bell, and G. M. Burt, "Control of multi-terminal dc transmission system based on voltage source converters," 9th IET International Conference on AC and DC Power Transmission (ACDC 2010), London, 2010, pp. 1-5.

[18] R. Chai, B. Zhang, J. Dou, "Improved DC Voltage Margin Control Method for DC Grid Based on VSCs," 2015 IEEE 15th International Conference on Environment and Electrical Engineering (EEEIC), Rome, 2015, pp. 1683-1687.

[19] K. Shinoda, X. Guillaud, S. Bacha, A. Benchaib, and B. Francois, "Modelling of a VSC-based multi-terminal HVDC network for dynamic stability analysis," COMPEL-The international journal for computation and mathematics in electrical and electronic engineering, vol. 36, no. 1, pp. 240-257, 2017.

[20] L. M. Castro and E. Acha, "A unified modeling approach of multi-terminal VSC-HVDC links for dynamic simulations of large-scale power systems," IEEE Transactions on Power Systems, vol. 31, no. 6, pp. 5051-5060, 2016. 
[21] Ch. S. V. S. Phani Kumar, T. Vinay Kumar, "A Novel on stability and fault ride through analysis of type-4 wind generation system integrated to VSC-HVDC link," International Journal of Applied Power Engineering (IJAPE), vol. 7, no. 1, pp. 52-58, 2018.

[22] A. Egea-Alvarez, J. Beerten, D. V. Hertem, O. Gomis-Bellmunt, "Hierarchical power control of multi-terminal HVDC grids," Electricaln Power System Research, vol. 121, pp. 207-215, 2015.

[23] V. Kaura and V. Blasko, "Operation of phase loop system under distorted utility conditions," IEEE Transactions on Industry Applications, vol. 33, no. 1, pp. 58-63, 1997.

[24] G. Shi, X. Cai, and Z. Chen, "Design and control of multi-terminal VSC HVDC for large offshore wind farms," Przeglad Elektrotechniczny, vol. 88, no. 12a, pp. 264-268, 2012.

[25] M. A. Djehaf, S. A. Zidi, Y. I. Djilani Kobibi, "Modeling of a multi-level converter based MTDC system for the study of power system steady-state and transient characteristics," Journal of Electrical Engineering, vol. 16, no. 1, pp. 116-124, 2016.

[26] C. Spallarossa, T. Green, C. Lin, and X. Wu, "A dc voltage control strategy for mme mtdc grids incorporating multiple master stations," 2014 IEEE PES T\&D Conference and Exposition, Chicago, IL, 2014, pp. 1-5.

[27] T. Nakajima and S. Irokawa, "A control system for HVDC transmission by voltage sourced converters," 1999 IEEE Power Engineering Society Summer Meeting. Conference Proceedings (Cat. No.99CH36364), Edmonton, Alta., Canada, 1999, pp. 1113-1119 vol.2.

[28] E. Prieto-Araujo, F. D. Bianchi, A. Junyent-Ferre, and O. Gomis-Bellmunt, "Methodology for droop control dynamic analysis of multi-terminal VSC-HVDC grids for offshore wind farms," IEEE Transactions on Power Delivery, vol. 26, no. 4, pp. 2476-2485, 2011. 